\title{
Productivity Gains from Training: The Views of Employers and Stakeholders
}

\author{
Maria Eliophotou Menon \\ ${ }^{1}$ Educational Administration and Policy, University of Cyprus, Cyprus \\ Correspondence: Maria Eliophotou Menon, Educational Administration and Policy, University of Cyprus, Cyprus. \\ E-mail: melmen@ucy.ac.cy
}

Received: January 26, 2013 Accepted: February 10, 2013 Available online: March 3, 2013

doi:10.11114/jets.v1i1.54

URL: http://dx.doi.org/10.11114/jets.v1i1.54

\begin{abstract}
The paper investigates the views of employers and stakeholders in Cyprus regarding the effect of training on productivity in their organisation. Qualitative research was used to collect information from 26 individuals who represented different types of employers (public sector institutions, semi-government institutions, small and large private organisations) and key stakeholders. Respondents discussed the different methods of training used in their organisation and the criteria used in selecting employees for training. In general, training was considered to have a positive effect on productivity by enhancing the skills and competencies of employees. However, very few organisations used quantitative methods in order to evaluate the effectiveness of training and measure its impact on productivity. Participants identified the problems which prevent training from having a positive impact on productivity.
\end{abstract}

Keywords: human capital, training, productivity

\section{Introduction and Aims of the Study}

The emergence of human capital theory in the late 1950s drew attention to the investment aspects of education and training, both at the private and the social level. Becker $(1964,1974)$ provided the rationale for treating human capital in the same way as physical capital, thus integrating human capital theory into mainstream economics. The treatment of educational investment as investment in human capital rests on the assumption that the additional education and training acquired by individuals will lead to an increase in their productivity, which will be rewarded with higher earnings. The higher earnings of educated workers are thus believed to reflect their superior productivity. Education and training are thought to raise productivity through the provision of skills and knowledge, which increase the efficiency and hence the value of the more educated.

In economics, a number of studies have attempted to provide evidence on the effect of education and training on productivity in an attempt to inform the literature and address the criticisms directed at the human capital model. In general, the existing literature has mainly focused on estimating the profitability of investment in education, with very few studies dealing with the impact of training on productivity (Colombo \& Stanca, 2008). In this context, studies seeking to measure the effect of training on productivity have employed quantitative models. However, such models have not provided evidence on employer perceptions regarding the effectiveness of training at the level of the individual firm.

Moreover, additional issues relating to the use and effectiveness of training have not been adequately addressed in the literature: One issue concerns the selection of different types of training by employers and the use of criteria in selecting employees for training programmes. Another important issue concerns the factors that possibly prevent training from having a positive effect on productivity at the workplace, or play a role in constraining this effect. The investigation of organisational practices and processes in relation to the use of training can help shed light on such issues. Information on the perceptions of employers, in particular, is important since employers make decisions regarding investment in training on the basis of their subjective views regarding the effectiveness of specific forms of training.

In this context, the present study seeks to investigate the views of employers and/or stakeholders regarding the effect of training on productivity, their decisions with respect to the provision of training, and their perceptions on 
different aspects of the link between training and productivity. Specifically, employers are asked to provide their views on the following:

- Methods of training and criteria used to select employees for participation in training programmes

- Ways of measuring the effectiveness of training

- The degree to which training has a positive effect on productivity

- The degree to which training is used to provide knowledge and skills that could have been acquired through education

- $\quad$ Problems which may limit the positive effect of training on productivity

The present study reports the findings of a qualitative study of employers and/or stakeholders in Cyprus on the effectiveness of training. In addition to examining employers' perceptions regarding the effect of training on productivity, the study aims at examining their views regarding the role of training in the organisation and its linkages to previous education acquired by employees. In this manner, we investigate the role of both education and training in providing employees with competencies valued by the labour market.

On a theoretical level, the findings of the present study can be used to provide a test for the main hypothesis postulated by human capital theory, according to which employers consider education and training an investment in human capital. This hypothesis is based on the assumption that employers are in a position to accurately estimate returns to education and training and use such information as a basis for investment decisions. On a policy level, the findings can shed light on existing links between education, training and the labour market. For instance, the study investigates the degree to which employers consider training to be necessary in order to provide knowledge and skills that could have been acquired through education. In this respect, the findings can be expected to have implications for the role of educational institutions in preparing graduates for the labour market.

\section{The Context}

Studies dealing with the effect of training on productivity commonly rely on econometric models, based on the use of wages as a proxy for productivity (see, for example, Brown, 1989; Lillard \& Tan, 1992; Lynch, 1992). In general, these studies find different types of training to have a positive effect on the earnings of workers. However, this research has been widely criticised for its reliance on wages as an indirect measure of productivity.

A different approach has been employed by authors who rely on firm-level data to investigate the effect of training on productivity. Bartel (1994) utilised data on the personnel policies and economic characteristics of 495 businesses in the manufacturing sector in the United States. She reported that companies which had implemented formal training programmes presented an increase of $6 \%$ in annual productivity, demonstrating a link between training and labour productivity not only at the level of the individual worker but also at the organisational level. In another early study, Bishop (1994) used data from the Employment Opportunities Pilot Projects Survey to examine the effect of company training offered to newly-hired employees on their productivity. According to the findings, newly-hired workers with relevant prior work experience, employer-sponsored formal training, and vocational education required less training and were more productive.

More recently, several studies have relied on panel data in an attempt to deal with problems affecting earlier work based on cross-sectional analysis, which did not control for the possible endogeneity of training. In the United States, Black and Lynch (2001), using panel data from 627 organisations, found training to have a positive effect on productivity in the first step of their analysis; no effects were found when they controlled for unobserved fixed effects. Positive effects of training on productivity were reported in Germany (Zwick, 2006), France (Ballot, Fakhfakh, \& Taymaz, 2006), Portugal (Almeida \& Carneiro, 2006) but not in Sweden (Ballot et al., 2006).

In the United Kingdom, Dearden, Reed and Van Reenen (2005) used a new panel of British industries (1983-1996) to examine the link between work-related training and productivity. They reported a statistically significant effect of private sector training on productivity: An increase of 1 percentage point in the proportion of trained employees was associated with an increase in value added per hour of approximately $0.6 \%$. Colombo and Stanca (2008) also found training to have positive effects on productivity, using a large national panel of Italian firms. They reported different effects within occupational groups, with the impact of training on productivity being significant only for blue-collar workers.

A small number of studies have attempted to evaluate the effectiveness of education and training through the investigation of the views of employers. Information on the subjective perceptions of employers is necessary for the interpretation of the decisions made by employers with respect to investments in human capital. Even though available studies of employers commonly focus on education, their findings have implications for training, 
especially in relation to the skills and competencies required by the labour market. For instance, in a study by Hesketh (2000), survey research was used to investigate employers' perceptions of graduate education and training in the United Kingdom. Based on the findings, the author concluded that employers did not always expect their graduate employees to possess all technical skills required for job effectiveness, and accepted that their organisations needed to take this into account in designing their training programmes.

Quality training programmes are thus expected to supplement and enhance the competencies of educated workers, making training an important investment in human capital. However, for training to have a positive impact on the productivity of workers, its quality needs to be assessed. The difficulty of evaluating the quality of training has been highlighted in the literature. Agbola and Lambert (2010) identified several challenges linked to the evaluation of training. These include the fact that the quality of skills is subjective and difficult to measure accurately and that training often takes place over a long time period, which makes it difficult to link success to the quality of training. The fact that quality is influenced by many interdependent factors (e.g. trainee characteristics such as commitment and enthusiasm) complicates the assessment of training even further.

Despite such difficulties, the literature suggests that certain key criteria can be used as the basis for the evaluation of different types of training. Agbola and Lambert (2010) highlighted the importance of responsiveness to industry skill needs in their assessment of Australia's vocational education and training. Gorman, Moore, Blake and Phillips (2004) drew attention to the need for structure in on-site training. Key elements of structure include the use of a structured plan with measurable training objectives, competent trainers and relevance of training to the company (Blanchard \& Thacker, 1999; Jacobs \& Jones, 1995; Moore, Blake, Phillips, \& McConaughy, 2003). However, the degree to which employers use these or other criteria in evaluating training has not been adequately addressed in relevant research. The present study attempts to shed light on employers' practices and perceptions in relation to the provision of training, and its presumed effects on productivity.

\section{Methodology}

Information on the views of employers was collected through semi-structured interviews with 26 individuals representing different employers and stakeholders in Cyprus. The sample was selected through criterion sampling since the individuals and organisations included in the sample represented the main categories of employers and stakeholders in Cyprus. As regards stakeholders, an attempt was made to include respondents with a significant role in the formulation of policy regarding labour productivity in Cyprus (e.g. Director of Cyprus Productivity Center, trade union representatives). It was considered important to include stakeholders in the sample because of the knowledge they possess on productivity issues due to their involvement with employers. Unions, in particular, have a major role in negotiating pay increases based on subjective estimates of productivity.

The sample included five main organisational categories, with private organisations divided into two categories (small/large), based on the number of people employed at the organisation. Companies with less than 30 employees were classified as small. Specifically, the following categories were included:

- Ten public sector institutions (three government ministries, two state higher education institutions, two government departments/agencies, three independent public service institutions)

- Five organisations representing significant stakeholders (one organisation representing employers and four trade unions)

- $\quad$ Three semi-government institutions

- Four large private organisations (two banks, one accounting firm, and one private university)

- Four small private organisations (printing firm, consulting firm, company promotion firm, electrical and mechanical contracting firm)

As previously mentioned, the above organisations were selected to represent the main categories of employers in Cyprus. There were no conflicts of interest associated with the researchers and the institutions included in the sample. The interviewer was selected after an examination of potential conflicts of interest, which did not show any links to any of the institutions included in the sample.

Respondents were either senior managers of the institutions or representatives selected directly by them. The questions used in the interview were formulated to meet the research objectives of the project and were pilot tested in three interviews. In questions involving key concepts, a definition was offered to respondents to avoid confusion regarding the precise meaning of the question. For instance, productivity was defined as output per unit of labour.

In order to minimise problems related with the use of interviews for data collection, only one interviewer was used. The interviewer was trained by a member of the research team and was observed during the pilot interviews. The 
interviews were recorded and transcribed for analysis. In cases where clarifications were required, the interviewees were contacted through the telephone. This also ensured that the views of respondents had been accurately recorded by the interviewer.

Ethical principles were taken into account in the design of the research. Emphasis was placed on two principles linked to the protection of interviewees, namely, the protection of individual autonomy and the respect of privacy (Howe \& Moses, 1999). As regards autonomy, respondents were provided with information on the type of research to be conducted and its aims prior to the interview. Based on this information, they decided whether they would participate in the research. In a further attempt to secure informed consent, the interviewer was instructed not to pressure interviewees to respond to all questions, if they did not feel they could provide relevant information. In relation to privacy, respondents remained anonymous throughout the process. The interviewer was instructed to emphasise the researchers' adherence to ethical principles prior to the interview.

Moreover, the selection of the interviewer was based on specific criteria, which included his knowledge of, and experience in, qualitative research. This was considered necessary in order to ensure that the interviewer would be aware of various aspects of the interview situation, such as power positions and power shifts during the interview. Discursive reflection on interviews was a part of the research process, with the interviewer recording specific incidents after the interview which he considered challenging or problematic (Cooper \& Burnett, 2006). These incidents were discussed with the main researcher after the completion of each interview.

After the transcription of interviews, the collected data were analysed through the constant comparative method where theory generation is grounded in that the data lead to the theory rather than vice versa (Glaser \& Strauss, 1967). In this context, the data are analysed inductively and used for the derivation of constructs. The fact that data were collected in a naturalistic setting (in this case, the offices of the respondents) allowed for the adoption of an ethnographic perspective in the investigation (LeCompte \& Preissle, 1993). Thus, respondents were able to provide information on their experience and their view of the situation. The software ATLAS.ti was considered to be the most appropriate for the purposes of the present research and was thus employed in the analysis of the data.

\section{Results}

The use of a qualitative research enabled respondents to discuss different aspects of the use of training at their organisations. Respondents provided factual evidence as well as personal opinions and evaluations regarding the value and effectiveness of training. The main findings of the in-depth interviews are presented below.

The duration of the training offered to employees by their employers differed considerably across firms, ranging from 10-15 hours per year to more than 11 days. As expected, small companies reported shorter training periods, with three out of four indicating that the duration of training was two days or less. The cost of training also varied considerably as small companies spent very small amounts, while large private companies invested more than 500,000 euros. It is interesting to note that most respondents representing public organisations were unable to provide information on time or money invested in training.

As regards types of training, several ways of offering training were mentioned by respondents (see Table 1). Most organisations reported using more than one method, resulting in 35 responses.

Table 1. Distribution of respondents according to types of training used

\begin{tabular}{|c|c|c|c|c|c|c|}
\hline Methods & $\begin{array}{l}\text { Public } \\
\text { sector }\end{array}$ & Semi-government & $\begin{array}{l}\text { Large } \\
\text { private }\end{array}$ & $\begin{array}{c}\text { Small } \\
\text { private }\end{array}$ & Stakeholders & Total \\
\hline Training programmes in Cyprus or abroad & 7 & 2 & 2 & 1 & 2 & 14 \\
\hline Training programmes for new employees & 1 & 1 & - & 1 & 1 & 4 \\
\hline $\begin{array}{l}\text { Training at human resource development } \\
\text { institutions }\end{array}$ & 1 & - & - & 1 & 1 & 3 \\
\hline Apprenticeship programmes & 1 & - & - & 1 & 1 & 3 \\
\hline Education at universities/colleges & - & 2 & - & - & - & 2 \\
\hline Long-distance programmes & - & - & - & 1 & - & 1 \\
\hline Personal study programmes & - & - & - & 1 & - & 1 \\
\hline Did not mention & 2 & 1 & 2 & - & 2 & 7 \\
\hline Total & 12 & 6 & 4 & 6 & 7 & 35 \\
\hline
\end{tabular}


The most popular method of training was the provision of training courses and seminars in Cyprus and abroad. This was observed in all kinds of organisations but especially in public companies, with seven out of ten reporting the use of this type of training. One reason for the use of this method by public organisations relates to the fact that there is provision for training expenses in their budgets, which they are expected to utilise. In many cases, respondents reported the use of on-site training programmes, which were considered necessary to offer employees specialised skills and knowledge not offered in higher education. As regards induction programmes for newly-hired employees, only four respondents mentioned their use. Training at human resource development institutions and apprenticeship programmes were mentioned by three respondents, while the remaining types of training were used by fewer organisations.

Table 2 provides information on the main criterion used in selecting employees for training. As seen in this table, there were mainly two participation criteria in the training offered to employees. Thus, most companies selected their trainees according to criteria based on the demands of the job or the need for broader development of individuals.

Table 2. Distribution of respondents according to criteria used to select trainees

\begin{tabular}{|c|c|c|c|c|c|c|c|}
\hline Criteria & & $\begin{array}{l}\text { Public } \\
\text { sector }\end{array}$ & Semi-government & $\begin{array}{l}\text { Large } \\
\text { private }\end{array}$ & $\begin{array}{c}\text { Small } \\
\text { private }\end{array}$ & Stakeholders & Total \\
\hline Job demands & & 3 & - & 3 & 2 & 3 & 11 \\
\hline $\begin{array}{l}\text { Need to } \\
\text { individuals }\end{array}$ & develop & 3 & 3 & 1 & 2 & 1 & 10 \\
\hline Trainee interest & & 2 & - & - & - & 1 & 3 \\
\hline Did not mention & & 2 & - & - & - & - & 2 \\
\hline Total & & 10 & 3 & 4 & 4 & 5 & 26 \\
\hline
\end{tabular}

Of 26 organisations, 11 gave the demands of the job as the most important factor in determining who will attend training. The comments of a bank manager are representative of the views of employers in this category:

Where we have productivity issues, we identify the area for improvement and the suitable training is offered. Mostly it is job-related. But even if it applies to the development of competencies (organisation, planning etc.), it is also job-related.

While this criterion was very popular among private organisations and stakeholders, it was less frequently utilised among public companies, with only three out of ten public organisations using it to select employees for training.

The second important criterion concerned the need to develop the employee's general skills and competencies. It was used by all semi-government organisations and three public organisations, with private companies considering the previous criterion more important. Those respondents who mentioned this criterion supported its use by referring to the need to develop broader social and communicative skills, as seen below:

It is broader in an attempt to improve the way of thinking rather than skills and knowledge. For instance, programmes aimed at improving behaviour, telephone skills, professional behaviour, emotional intelligence... These are programmes dealing with the soft qualities of people and not the technical ones.

(Manager at public university)

At a small number of organisations, it is the interest of the employee that served as the main criterion for participation in training programmes. This was the case in three organisations, two public and one stakeholder.

Of 26 organisations, only two used systematic methods in evaluating training. In the first case, a manager at a semi-government organisation (provider of public good) referred to tests used after the training is completed, mentioning a sequence of stages. The final stage consisted in measuring the effects of training on the performance of the organisation.

The first stage is the reaction, which we measure in relation to the satisfaction of respondents through a questionnaire. The second is learning, which we measure through tests, especially in relation to 
technical aspects. And then we reach the third stage, the transfer to work, the application of knowledge, which we will do for large training programmes because it is very expensive and time consuming to measure at such a large organisation. At the fourth stage, you measure the effects on the results of the organisation.

In the second case, a bank manager referred to the use of tests but also mentioned the use of subjective evaluations made by the superiors of the trained employee. In all other cases, respondents stated that their organisations used subjective methods and especially observation to assess the effects of training on productivity. Most pointed out that it was very difficult to evaluate training and that they were not aware of methods that would allow them to accurately assess the effects of training on productivity. Some respondents felt that it was impossible to measure these effects accurately because of the difficulties involved.

We do not have a way but we see the difference through the observation of the person we sent for training. It is through experience that we assess.

(Manager at public organisation)

No. There is no evaluation after taking a course, to determine its effects. Because many things are not measurable. Very few things can be measured and I do not know what happens when someone attempts to measure the productivity of the employee in the public sector, if there is a way to measure it. I believe it is extremely difficult.

(Manager at public organisation, Ministry)

I do not have the time to do it. It does not concern me. I have heavy workload continuously. I take it for granted that when a colleague spends time on a certain programme, he/she will improve. Some things are not measurable.

(Manager at large private university)

The only way is to observe when he/she applies it every day, then you realise to what extent he/she benefited. Usually they improve and we see the improvement on a practical level.

(Manager at small private electrical and mechanical contracting firm)

No. In other words, we work trying to improve productivity but it is all random and unplanned. Even though we aim at this at some level, the way we measure training and what we expect from it are not rationalistic.

(Union Manager)

Despite the reported inability of employers to measure the impact of training on productivity, almost all employers participating in the study expressed their conviction that training had a considerable effect on productivity. For some respondents, this conviction appeared to be based on the (mistaken) belief that any investment in human capital will yield returns.

By definition, efficiency and effectiveness will increase with training.

(Manager at large private university)

Of course. I believe it improves it. I believe that training is worth any cost... I do not see it as a cost but as an investment.

(Manager at public organisation)

Several participants pointed to examples of individuals or groups benefiting from training in their organisation. Respondents referred to the importance of training in technical and social skills, pointing to cases where employees were able to perform their jobs more efficiently and effectively after undergoing training. In many cases, managers drew attention to the importance of criteria used in the design of training so that training can meet its intended goals.

Of course, training is worth the cost. Especially in relation to the application of new systems and procedures, when we train on new software, for instance, the benefit is immediate, i.e., through training, we have an outcome like the better use of our systems, better performance on the part of our staff, we avoid questions or difficulties. Especially in technical education, the link is very strong.

(Bank manager)

Recently we had training for many of our employees on things like communication, team work, which involved issues of emotional intelligence... The staff benefited a lot and the supervisors reported that 
after this training, productivity and team work increased.

(Manager at semi-government organisation)

Appropriate training includes technical education, I mean practical work and after the programme, there is evaluation and continuation of knowledge; this has great returns in relation to productivity and in relation to cost.

(Manager at small private consulting firm)

When there is careful selection with respect to where someone will go for training, and there is a match between needs at the workplace and the real needs of individuals, then it is taken for granted that productivity will increase at the workplace.

(Manager at semi-government organisation)

Only two respondents did not express a clear view on the effect of training on productivity. Of these, one was a manager in the public sector and the other was the manager of a small company.

Respondents were also in agreement regarding the extent to which training is used to impart knowledge and skills that could have been acquired through education. All but one manager believed that this was the case to a great extent. However, after an initial agreement, respondents were divided into two groups: those who considered this a weakness of (higher) education and those who expected this to be the case, suggesting that it was the responsibility of employers to offer more specialised skills to their employees. The following comments are representative of the first group:

Education provides the required knowledge to a degree of $70-80 \%$. There is a $20 \%$ that the employers need to cover. This should have been $5 \%$.

(Manager at small private consulting firm)

We provide the education they should have received to a great extent; especially in relation to the development of skills that we believe that they should have acquired through schools, through universities.

\section{(Bank manager)}

In the second group, respondents highlighted the difference between the type of skills and knowledge offered by universities and those required at the workplace. Specifically, universities were considered to focus on general and theoretical knowledge, which was not sufficient to meet the technical and specialised needs of employers. In this context, participants referred to the importance of the employee possessing personal skills and competencies such as the ability to adjust to changes in the external environment. Formal education was expected to develop such qualities in individuals, thus allowing them to be more productive at the workplace.

We train employees on specific topics. Schools offer more general topics. It is necessary for someone to have general education but we train them on specialised topics that we deal with as a department.

(Bank manager)

I do not have great expectations of knowledge from education because a university can provide a foundation and a critical approach on the part of the individual. An individual must acquire learning tools, ways of thinking and looking for knowledge. Thus, we do not expect knowledge to have immediate application in our work.

(Manager at large private accounting firm)

One must not expect the educational system to achieve the perfect match between the needs of the labour market and the competencies it offers. What is important is that the educational system shapes individuals who can adjust to new circumstances in the framework of rapid developments.

(Manager at semi-government organisation)

In response to the question concerning factors which limit the positive effect of training on productivity, respondents referred to several problems or limitations. Five main categories of problems were identified: The first factor was mentioned by six individuals and concerned the individual characteristics of the trainee. Most respondents discussed the importance of motivation which affects the employees' willingness to learn and apply the acquired skills and knowledge in the workplace. 
You can send a person for training and he/she may come back and not show the expected interest and then the training goes to waste. So we may take five people, send them to training on a new technology and one may be interested and the others not.

(Manager at small private electrical and mechanical contracting firm)

The second group of problems concerned the work environment and the quality of relationships among people. Specifically, four respondents referred to the fact that the climate was not supportive for employees and in some cases, identified problems in the relationship between an employee and his/her superiors. It is interesting to note that this problem was highlighted by managers of relatively large companies, indicating that the work climate may be more important as an influence on productivity in larger organisations.

The third group of problems also concerned the organisation, in relation to its structure, processes and other characteristics. A manager at a semi-government organisation drew attention to this, saying that if an employee received training on organisational leadership, it could be impossible for him/her to put into practice what he/she had learned because of hindering organisational structures and characteristics. Two union managers pointed to problems associated with organisational structures and processes, referring to weaknesses in leadership, evaluation and utlilisation of technology. In addition, four respondents believed that the effect of training on productivity was negatively affected by the lack of incentives in the organisation. Managers at public or semi-government organisations were more likely to identify this problem, pointing to the fact that employees did not have the incentives for using their training to improve their performance.

The quality of training programmes was also considered an important factor by five respondents. Managers of different organisations (semi-government, bank, small private, public and stakeholder organisation) referred to the fact that several characteristics of the training offered could affect the extent to which it had an impact on worker productivity. Characteristics mentioned by respondents include the trainer's expertise and experience, the content of the training and the degree to which the training matches the personal needs of the trainee and the aims of the organisation. It is interesting to note that only one respondent referred to the lack of measurable objectives for training as a hindering factor.

Overall, the results point to interesting similarities and differences between the public and private sector organisations included in the sample. Due to the nature of the study and the small number of organisations included in each sub-category, it is not possible to identify differences between different organisational categories. However, a tentative comparison between public and private sector institutions can be made. Table 3 provides a summary of the main findings, as they relate to the public and private sector in Cyprus.

Table 3. Characteristics of public and private sector organisations in Cypus, in relation to the use of training

\begin{tabular}{|c|}
\hline Public Sector \\
\hline $\begin{array}{l}\text { - Use of formal training programmes for existing employees } \\
\text { - } \quad \text { Limited training for new employees } \\
\text { - } \text { More likely to be unable to provide exact figures in relation to time and money invested in trainining } \\
\text { - } \quad \text { Sse of empirical methods to measure the effectiveness of training } \\
\text { - } \quad \text { More likely to consider individual needs in the selection of employees for training } \\
\end{array}$ \\
\hline Private Sector \\
\hline $\begin{array}{l}\text { - Use of formal training programmes for existing employees } \\
\text { - } \quad \text { Limited training for new employees } \\
\text { - } \quad \text { Use of empirical methods to measure the effectiveness of training } \\
\text { - } \quad \text { More likely to consider the demands of the job in the selection of employees for training } \\
\text { effectiveness of training }\end{array}$ \\
\hline
\end{tabular}


As seen in the table, the main differences between the public and the private sector relate to the main criterion used in selecting employees for training (individual needs versus demands of the job), and the main problem considered to have an impact on the effectiveness of training (lack of incentives versus organisational climate). Moreover, public sector officials were more likely to be unable to provide exact figures on time and money invested in training at their organisation.

\section{Conclusions and Implications}

The present study attempted to investigate the views of employers regarding the effect of training on productivity in their organisations. Qualitative research was used in an attempt to identify the beliefs and views of respondents in relation to the use of training at the organisation.

According to the findings, large organisations invested more in training than smaller ones. The most popular type of training was the provision of specialised programmes inside or outside the country. The selection of employees for training programmes was mainly based on two criteria, the demands of the job and the need for broader development of individuals.

Despite the lack of methods for measuring the impact of training on productivity, almost all respondents were convinced that training had a positive effect on the effectiveness of their workers. This renders support to the human capital hypothesis that individuals and/or organisations spend on education and training for the sake of future returns (Blaug, 1976). In the present study, it is the expectation of future returns that drove employers to invest in training programmes. To justify their faith in the value of training, respondents mainly referred to cases of employees who had benefited from training in that they were able to perform their jobs more effectively and efficiently after being trained. It thus appears that the evaluation of the effectiveness of training in Cyprus is largely based on empirical assessments of its quality.

The majority of respondents believed that training is used to impart knowledge and skills that could have been acquired through education. This was not necessarily associated with a negative stance towards education in that most respondents expected this to be the case, drawing attention to the difference between the skills and knowledge offered by universities and those required at the workplace. The former were considered to be more general and theoretical, and the latter more specialised and job-related.

The main factors considered to limit the positive effect of training on productivity at the workplace include the trainee's lack of motivation, the quality of the work environment, organisational structure and processes, and the lack of incentives. While problems relating to the individual's personal characteristics appeared to apply to all types of organisations included in the sample, problems stemming from the lack of incentives were prevalent in the public sector, which is commonly linked to lower levels of productivity.

Due to the qualitative nature of the study, the results reported in this paper can be considered preliminary. However, the fact that the sample covered the main categories of employers in a small country suggests that certain tentative policy implications can be drawn: First, the findings point to the need for measures that can enhance the positive effect of training on productivity. There appears to be a need for the development of systematic and accurate methods for the evaluation of the effectiveness of training at the level of the organisation. While the use of observation may be an important indication of effectiveness, the adoption of additional methods is necessary in order to provide a more objective and accurate evaluation of the effectiveness of training. This could be done, for instance, through the application of standardised tests offered to employees before and after their training. The measurement of the returns to training will, in turn, allow employers to make more informed decisions regarding future investments in training.

Second, at the level of the organisation, the factors limiting the positive effect of training on productivity, as identified by respondents, highlight the importance of changes in organisational structures and practices. Given the significance attached to personal characteristics as a productivity-influencing factor, it is necessary for employers to improve their hiring policies in an attempt to identify those candidates more likely to take advantage of the skills and knowledge offered through training. This is imperative in the public sector of Cyprus, which has been criticised for maintaining bureaucratic and inefficient practices, in relation to the selection and the evaluation of its staff. In addition, it is important for employers to receive accurate and up-to-date information on the training options available to them and the degree to which these options can meet their training needs. The lack of relevant information may prevent employers from selecting training options that will maximise the return to training.

The findings also have implications for the link between education, training and the labour market. Even though respondents were not critical of the fact that training was used to impart skills and knowledge that could have been acquired through education, the current economic crisis and the deteriorating employment prospects of university 
graduates are likely to put greater pressure on educational institutions to respond to the demands of the labour market. In this context, universities and schools will need to consider changes in their orientation and programmes so that graduates are better prepared to meet the needs of employers. In particular, the acquisition of skills and knowledge valued by the labour market can be expected to enhance the employability of graduates and improve organisational efficiency and effectiveness.

Overall, the present study draws attention to the importance of examining the perceptions of employers regarding the use and effectiveness of training in the organisation. The use of a qualitative approach proved to be useful in identifying personal views and beliefs of employers and stakeholders involved in decisions regarding the use of training. However, the qualitative nature of the research limits the generalisability of the findings, pointing to the need for further research on the topic. Quantitative studies can help corroborate existing findings and provide more concrete evidence on the effects of training on productivity at different types of organisations. Moreover, a quantitative methodology will be appropriate for the collection of information from different individuals in the same organisation. This, in turn, will allow for a comparison of perspectives regarding the use and effectiveness of training in various institutions.

Despite their preliminary nature, the findings of the present study suggest that the investigation of the views of employers can help provide an explanation for the decisions made by employers and stakeholders regarding investments in training. The understanding of these decisions can inform the design of policy measures aimed at the adoption of more effective and efficient training practices. Given the current economic crisis and its continuing impact on managerial decisions and priorities, it is necessary for organisations to collect and utilise the evidence that will improve their decision making regarding investments in human capital.

\section{References}

Agbola, F. W., \& Lambert, D. K. (2010). Skilling Australia for the future? A study of quality assurance in Australia's vocational education and training. Journal of Vocational Education and Training, 62(3), 327-349. http://dx.doi.org/10.1080/13636820.2010.509805

Almeida, R., \& Carneiro, P. (2006). The return to firm investment in human capital. World Bank Policy Research Working Paper no. 3851.

Ballot, G., Fakhfakh, F., \& Taymaz, E. (2006). Who benefits from training and R\&D, the firms or the workers? British Journal of Industrial Relations, 44(3), 473-495. http://dx.doi.org/10.1111/j.1467-8543.2006.00509.x

Bartel, A. (1994). Productivity gains from the implementation of employee training programs. Industrial Relations, 33(4), 411-425. http://dx.doi.org/10.1111/j.1468-232X.1994.tb00349.x

Becker, G. (1964). Human capital. Princeton, NJ: Princeton University Press.

Becker, G. (1974). The economic approach to human behaviour. Chicago: University of Chicago Press.

Bishop, J. H. (1994). The impact of previous training on productivity and wages. In L. M. Lynch (Ed.), Training and the private sector, International comparisons (pp. 161-199). Chicago: University of Chicago Press.

Black, S. E., \& Lynch, L. M. (2001). How to compete: The impact of workplace practices and information technology on productivity. Review of Economics and Statistics, 83(3), 434-445. http://dx.doi.org/10.1162/00346530152480081

Blanchard, P. N., \& Thacker, J. (1999). Effective training: Systems, strategies and practices. Upper Saddle: Prentice-Hall.

Blaug, M. (1976). The empirical status of human capital theory: A slightly jaundiced survey. Journal of Economic Literature, 14(3), 827-855.

Brown, J. N. (1989). Why do wages increase with tenure? American Economic Review, 79(5), 971-991.

Colombo, E., \& Stanca. L. (2008). The impact of training on productivity: Evidence from a large panel of firms. Working paper 134, University of Milano-Bicocca, Department of Economics.

Cooper, N., \& Burnett, S. (2006). Using discursive reflexivity to enhance the qualitative research process. Qualitative Social Work, 5, 111-129. http://dx.doi.org/10.1177/1473325006061541

Dearden, L., Reed, H., \& Van Reenen, J. (2005). The impact of training on productivity: Evidence from British panel data. London, UK: LSE Research Online. Retrieved from: http://eprints.lse.ac.uk/archive/00000779.

Glaser, B. G., \& Strauss, A. L. (1967). The discovery of grounded theory: Strategies for qualitative research. Chicago: Aldine Publishing Company. 
Gorman, P., Moore, R., Blake, D., \& Phillips, G. M. (2004). An empirical study of the effectiveness of publicly-funded 'strucured on-site training': Implications for policy and practice. Journal of Vocational Education and Training, 56(3), 387-408. http://dx.doi.org/10.1080/13636820400200261

Hesketh, A. J. (2010). Recruiting an elite? Employers' perceptions of graduate education and training. Journal of Education and Work, 13(3), 245-271. http://dx.doi.org/10.1080/713676992

Howe, K., \& Moses, M. (1999). Ethics in educational research. Review of Research in Education, 24, 21-60.

Jacobs, R. L., \& Jones, M. L. (1995). Structured on-the-job training: Unleashing employee expertise in the workplace. San Francisco: Berrett-Koehler.

LeCompte, M. D., \& Preissle, J. (1993). Ethnography and qualitative design in educational research. New York: Academic Press.

Lillard, L. A., \& Tan, H. W. (1992). Private sector training: Who gets it and what are its effects? Research in Labour Economics, 13, 1-62.

Lynch, L. (1992). Private sector training and the earnings of young workers. American Economic Review 82(1), 299-312.

Moore, R., Blake, D., Phillips, G. M., \& McConaughy, D. (2003). Training that works: Lessons from California's employment training panel program. Kalamazoo: Upjohn.

Zwick, T. (2006). The impact of training intensity on establishment productivity. Industrial Relations, 45(1), 26-46. http://dx.doi.org/10.1111/j.1468-232X.2006.00412.x

\section{(cc) $\mathrm{Br}$}

This work is licensed under a Creative Commons Attribution 3.0 License. 